\title{
Creep of $\alpha_{2}+\beta$ Titanium Aluminide Alloys
}

\author{
Anthony W. THOMPSON and Tresa M. POLLOCK
}

Department of Metallurgical Engineering and Materials Science, Carnegie Mellon University, Pittsburgh, PA 15213, U. S. A.

(Received on March 1, 1991; accepted in final form on May 24, 1991)

\begin{abstract}
The interest in titanium aluminide alloys includes elevated temperature applications, for which creep resistance is a primary property. Tests have been made between 650 and $870^{\circ} \mathrm{C}$ on a variety of microstructures of Ti-24Al-11 Nb and Ti-25Al-10 Nb-3Mo-1V (at\%) alloys. It has been found that microstructure plays an important role in creep of these materials, so that thermal and mechanical history is important. Stress exponents for power-law creep, and apparent creep activation energies, have been determined for these alloys. As is usually found in structural alloys microstructural characteristics which increase ductility and toughness at low temperature tend to accelerate creep considerably, particularly the presence of $\beta$ phase, and most notably when arranged as locally-continuous $\beta$ films between plates of the $\alpha_{2}$ phase. Solution treatment in the $\beta$ phase provided optimum creep resistance, but cooling rate effects were different in the two alloys considered. Comparison to near- $\alpha$ titanium alloys developed for creep resistance, shows that the aluminide alloys have better performance, especially above $700^{\circ} \mathrm{C}$.
\end{abstract}

KEY WORDS: titanium aluminides; creep; microstructure; temperature dependence; stress dependence.

\section{Introduction}

There has been considerable recent interest in the development of advanced titanium aluminide alloys based on $\mathrm{Ti}_{3} \mathrm{Al}$ for aircraft engine components and other high temperature applications. It has been found that $\mathrm{Ti}_{3} \mathrm{Al}$ retains adequate creep strength to much higher temperatures than do conventional titanium alloys, but it exhibits low ductility at room temperature. ${ }^{1,2)}$ Therefore, development of aluminide alloys has been directed to combinations of room temperature ductility and elevated temperature creep strength. One alloying approach has been the addition of $\beta$-phase stabilizing elements such as niobium to $\mathrm{Ti}_{3} \mathrm{Al}$. Alloying of this kind has proven successful in providing some property improvements, in alloys such as $\mathrm{Ti}-24 \mathrm{Al}-11 \mathrm{Nb}$ (values are at $\%$ or $\mathrm{a} / \mathrm{o}$ ), and more recently, the alloy $\mathrm{Ti}-$ $25 \mathrm{Al}-10 \mathrm{Nb}-3 \mathrm{~V}-1 \mathrm{Mo}$ was developed with further additions of $\beta$ phase stabilizers. ${ }^{1-5)}$ These alloys are referred to below as $\mathrm{Ti}-24-11$ and $\mathrm{Ti}-25-10-3-1$, respectively.

For conventional titanium alloys, most studies on creep behavior in recent years have been performed on near- $\alpha$ alloys, such as Ti-6242S ${ }^{6)}$ and IMI $685,{ }^{7)}$ and have shown that the creep resistance of such alloys is strongly dependent on microstructure. It was found, in these and other studies, ${ }^{8,9)}$ that Widmanstätten microstructures, obtained by solution treating above the $\beta$ transus, produced creep resistance at high temperatures superior to that provided by equiaxed microstructures obtained by processing in the $\alpha+\beta$ phase field. It was also found that creep resistance is maximized at intermediate cooling rates from the $\beta$ solution treatment temperatures.
For alloys based on $\mathrm{Ti}_{3} \mathrm{Al}$, on the other hand, relatively few data on creep behavior have been published. The pioneering work of Mendiratta and Lipsitt ${ }^{10}$ was performed to investigate the steady-state creep behavior of $\mathrm{Ti}_{3} \mathrm{Al}$ and $\mathrm{Ti}_{3} \mathrm{Al}+10 \mathrm{w} / \mathrm{o} \mathrm{Nb}$ (about $5 \mathrm{a} / \mathrm{o} \mathrm{Nb}$ ) in the temperature range of 550 to $825^{\circ} \mathrm{C}$. The $\mathrm{Ti}_{3} \mathrm{Al}$ phase, called $\alpha_{2}$, may in alloys be accompanied by the bcc $\beta$ phase. In that study, ${ }^{10)}$ it was shown that at temperatures above $700^{\circ} \mathrm{C}$, the stress exponent $n$ of the power-law creep equation indicated a transition in mechanism, and in the high stress and temperature regime addition of $\mathrm{Nb}$ increased the apparent activation energy for creep deformation. Subsequent work, ${ }^{11,12)}$ together with considerable information in the form of contract research reports, has been reviewed. ${ }^{13-15)}$

In two recent investigations, ${ }^{16,17)}$ room temperature tensile and elevated temperature creep studies have been performed on various microstructures of Ti-24-11 and Ti-25-10-3-1. These studies evidenced particular interest in the creep behavior of these alloys at the temperatures between 650 and $870^{\circ} \mathrm{C}$, since the use of conventional titanium alloys has generally been restricted ${ }^{5)}$ to temperatures below $600^{\circ} \mathrm{C}$. In the present overview, the primary focus is the influence of microstructure, since it is evident ${ }^{14)}$ that this factor is very important in creep of these alloys; identification of stress and temperature effects on creep behavior is also included.

\section{Experiments}

Composition and processing of the $\mathrm{Ti}-24-11$ and Ti-25-10-3-1 alloy materials has been presented previously. ${ }^{16,17)}$ A few tests were performed on as-received 
material, which had been processed in the $\alpha_{2}+\beta$ phase field. Preparation of other microstructures was accomplished by resolution treating in either the $\alpha_{2}+\beta$ or the $\beta$ phase field and controlling the cooling rate from the solution treatment temperature. Transformed $\beta$ microstructures were produced by a $1 \mathrm{~h} / \beta$ solution treatment followed by one of the following cooling schemes: slow or furnace cooling, SC; controlled cooling, $\mathrm{CC}$; air cooling, $\mathrm{AC}$. The $\mathrm{SC}, \mathrm{CC}$ and $\mathrm{AC}$ treatments produced average cooling rates of $0.1,0.5$, and $10 \mathrm{~K} / \mathrm{sec}$, respectively, when measured between the solution treatment temperature and $760^{\circ} \mathrm{C}$. The $\alpha_{2}+\beta$ microstructures were produced by solution treating within the $\alpha_{2}+$ $\dot{\beta}$ phase field anet the same cooling schemes as above. (The $\beta$ transus temperature for Ti-24-11 is about $1125^{\circ} \mathrm{C}$ and for Ti-25-10-3-1 is about $1075^{\circ} \mathrm{C}$.) For the Ti-2411 , two solution treating times were used in the $\alpha_{2}+\beta$ heat treatment to vary the size of $\alpha_{2}$ plates.

Conventional creep testing of $\mathrm{Ti}-24-11$ and $\mathrm{Ti}-25-$ 10-3-1 alloys was conducted, using constant-load techniques in air. Specimens had a $6.4 \mathrm{~mm}$ diameter and a $37 \mathrm{~mm}$ effective gage length, with sufficient metal removal during machining to ensure that contaminated surfaces were removed. Test procedures followed ASTM E139-79. Creep strain was measured using a SLVC transducer which allowed a strain resolution of $5 \times 10^{-6}$. For tests which were continued to fracture, the fracture surfaces were examined in a scanning electron microscope; thin foils were examined by transmission electron microscopy (TEM) for various creep strains.

\section{Results and Discussion}

\subsection{Microstructures}

The microstructures obtained from the various heat treatments were as follows. Solutionizing in the $\beta$ phase field and air cooling produced fine acicular $\alpha_{2}$ plates arranged in a Widmanstätten basketweave morphology, while slower cooling rates resulted in coarser $\alpha_{2}$, less retained $\beta$ phase, and a transition from basketweave to aligned colony $\alpha_{2}$ structures. Solutionizing in the $\alpha_{2}+\beta$ phase field produced elongated primary $\alpha_{2}$ plates in a Widmanstätten basketweave morphology, surrounded by a "transformed $\beta$ " matrix similar to that of $\beta$ solution treated microstructures. This transformed $\beta$ constituent comprised secondary acicular $\alpha_{2}$ plates as well as some retained $\beta$ phase. When nucleation of individual plates becomes slow, "sympathetic" nucleation ${ }^{18)}$ gives rise to parallel $\alpha_{2}$ plates of common orientation, which are called colonies.

Examples of these microstructural types are contained in Fig. 1. The relatively fine Widmanstätten $\alpha_{2}$ plates formed on cooling from the $\beta$ phase are shown in Fig. 1 (a), indicating that the transformation is dominated by easy nucleation. Cooling from the $\alpha_{2}+\beta$ two-phase region typically gives coarser $\alpha_{2}$ plates, although still of Widmanstätten character, indicating that growth of the plates is more significant, Fig. 1(b); note also in this figure that some primary $\alpha_{2}$ has formed at prior $\beta$ grain boundaries. Figure 1(c) shows that with more working in the $\alpha_{2}+\beta$ two-phase region, larger and more globular primary $\alpha_{2}$ forms at grain boundaries, ${ }^{18}$ ) while $\alpha_{2}$
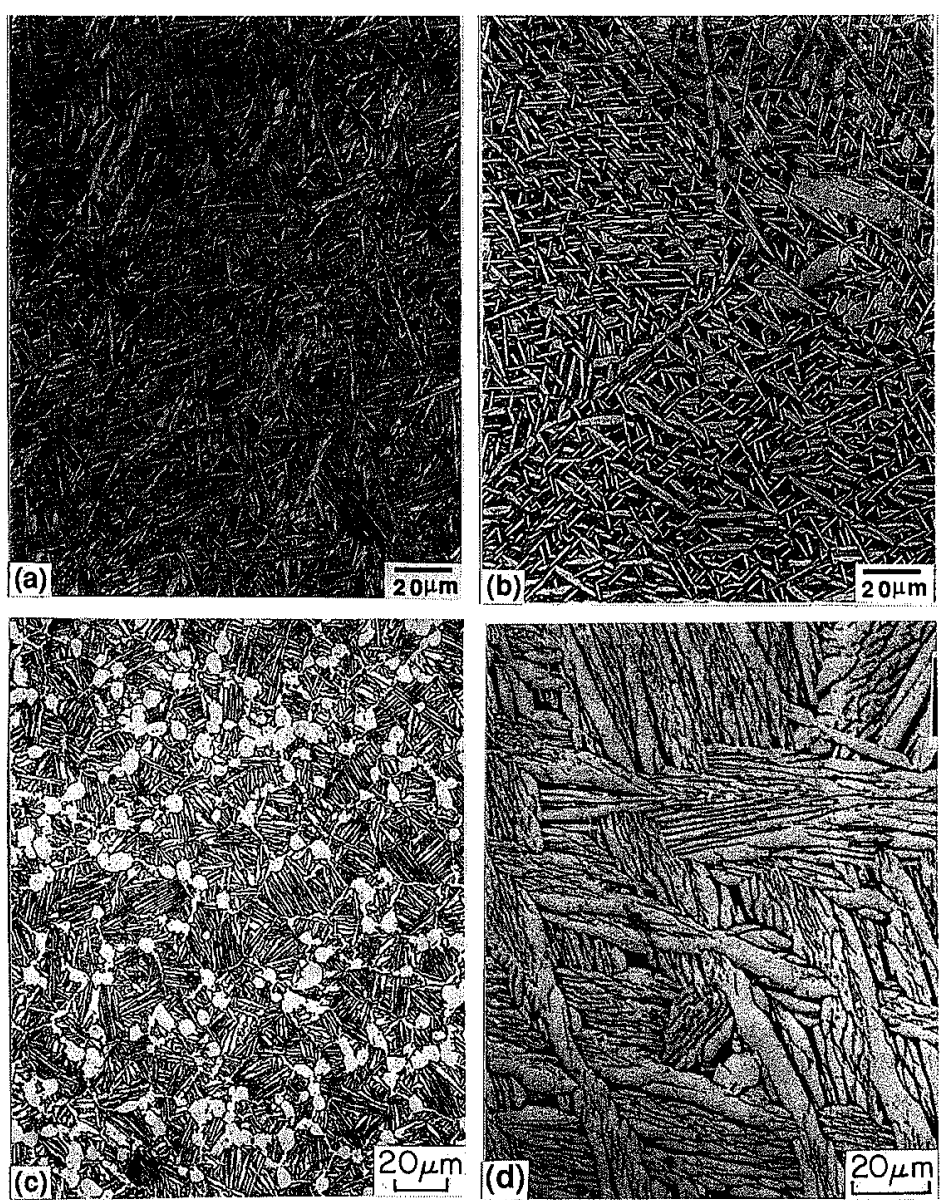

Fig. 1.

Examples of microstructural range observed in $\alpha_{2}+\beta$ titanium aluminide alloys. (a) Widmanstätten or basketweave morphology of $\alpha_{2}$ plates, formed in Ti-25-10-3-1 on cooling from the $\beta$ phase at $0.5 \mathrm{~K} / \mathrm{sec}$. (b) Coarser Widmanstätten $\alpha_{2}$ plates, formed in Ti-25-10-3-1 on cooling from the $\alpha_{2}+\beta$ two-phase region at $0.5 \mathrm{~K} / \mathrm{sec}$. (c) Primary $\alpha_{2}$ and "packet" $\alpha_{2}$ plates in Ti-25-10-3-1 cooled from the $\alpha_{2}+\beta$ two-phase region. (d) Colonies of $\alpha_{2}$ plates in Ti-24-11 cooled from $1000^{\circ} \mathrm{C}$ (low in the $\alpha_{2}+\beta$ two-phase region) at $5 \mathrm{~K} / \mathrm{sec}$ 
plates show some grouping into "packets" of parallel plates in most prior $\beta$ grains. This is a common ashot-worked microstructure. Finally, colonies containing a number of $\alpha_{2}$ plates with a common orientation can be formed by cooling from low in the $\alpha_{2}+\beta$ two-phase region, as in Fig. 1(d). More detailed light and electron micrographs of these structures have been presented elsewhere. ${ }^{16-18)}$.

It should be mentioned that the retained $\beta$ phase in $\mathrm{Ti}_{3} \mathrm{Al}$ alloys may be ordered or disordered. The details of retained $\beta$ phase were not investigated via TEM in the studies discussed here, but it is believed from earlier reports $^{19-23)}$ that retained $\beta$ phase in Ti-25-10-3-1 has a fully transformeđordered structure (B2, $\mathrm{CsCl}$ type). It was shown in those papers that addition of $\beta$ stabilizers such as $\mathrm{Mo}, \mathrm{Nb}$, or $\mathrm{V}$ tended to result in the ordering of the $\beta$ phase to a $\mathbf{B} 2$ structure. In the work of Strychor et al., ${ }^{22,23)}$ the nature of $\beta$ phase ordering even in water-quenched specimens of Ti-27.8Al-11.7Nb (a/o) was confirmed by the observation of superlattice reflections characteristic of a $\mathrm{CsCl} \mathrm{B} 2$ structure. This ordering has been observed in $\mathrm{Ti}_{3} \mathrm{Al}+\mathrm{Nb}$ alloys whose $\mathrm{Nb}$ contents lie between about 15 and $35 \mathrm{w} / \mathrm{o}$, even though the extent of this field at the high $\mathrm{Nb}$ end is still undetermined in detail. ${ }^{22,23)}$ On the other hand, TEM evidence to date in Ti-24-11 has typically shown that the $\beta$ phase may or may not be ordered. Evidently the Ti-24-11 composition lies near the threshold composi$\operatorname{tion}^{23)}$ for ordering to take place under the heat treating conditions typically studied.

\subsection{Creep Properties}

A principal goal of the two studies emphasized here ${ }^{16,17)}$ was identification of microstructure effects in creep. The role of microstructure can be illustrated by strain-time curves for Ti-25-10-3-1, as shown in Fig. 2. Here, two temperatures and stress levels both show that creep is dramatically affected by the microstructure of the material. Most of the creep curves have a classical appearance with a primary or transient period followed by a steady state regime. It is useful in Fig. 2 to interpret creep behavior in terms of two processing parameters: (1) solution treatment temperature ( $\left.\beta / \mathrm{SC} v s . \alpha_{2}+\beta / \mathrm{SC}\right)$, and (2) cooling rate from the $\beta$ region ( $\beta / \mathrm{AC}, \mathrm{CC}$, and $\mathrm{SC})$. At both temperatures, the $\alpha_{2}+\beta$ processed microstructure $\left(\alpha_{2}+\beta / \mathrm{SC}\right)$ which had elongated primary $\alpha_{2}$ grains shows lower creep resistance, when compared to the $\beta$ solution treated microstructure $(\beta / \mathrm{SC})$, although the magnitude of the effect of solution treating process was much greater at $760^{\circ} \mathrm{C}$, Fig. 2(b).

Creep resistance, however, cannot be characterized by the $\beta$ solution treatment alone. The effect of cooling rate from the $\beta$ phase region on microstructure and its role in creep performance needs to be taken into account. Creep resistance increased with decreasing cooling rate at $760^{\circ} \mathrm{C}$, Fig. 2(b), and thus creep resistance of the slow-cooled colony microstructure $(0.1 \mathrm{~K} / \mathrm{sec})$ was significantly improved. However, at $650^{\circ} \mathrm{C}$, as shown in Fig. 2(a), creep resistance increases with increasing cooling rate through a maximum at an intermediate cooling rate of $0.5 \mathrm{~K} / \mathrm{sec}$ which produced a basketweave

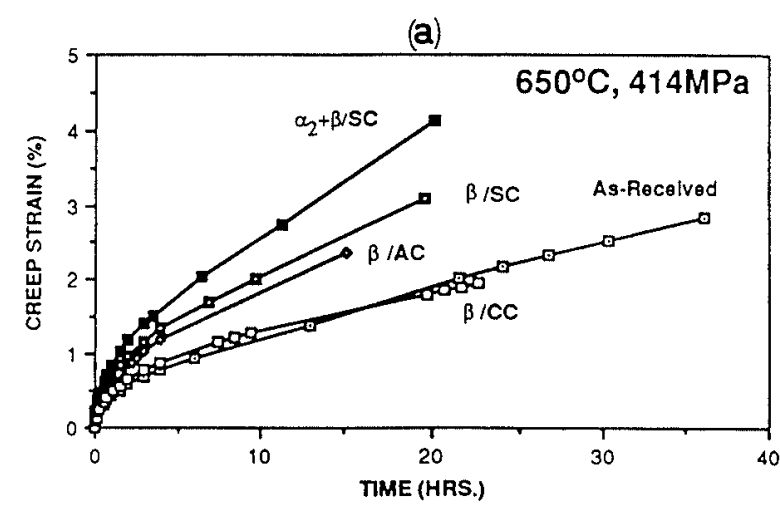

(b)

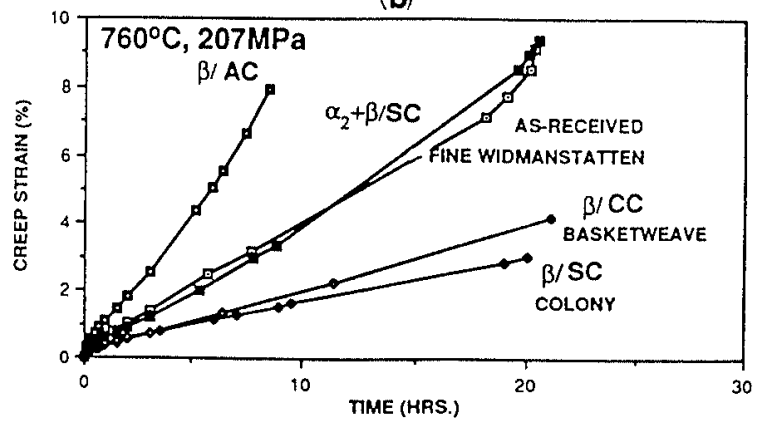

Fig. 2. Creep strain as a function of time, for Ti-25-10-3-1 Each curve is labeled with the microstructure as (solution treatment)/(cooling rate). (a) Test at $650^{\circ} \mathrm{C}$, $414 \mathrm{MPa}(60 \mathrm{ksi})$ stress. (b) Tests at $760^{\circ} \mathrm{C}, 207 \mathrm{MPa}$ (30 ksi) stress. Microstructural descriptions added to some curves. From Ref. 16).

microstructure. The effect of cooling rate is discussed further below.

\subsection{Stress Dependence}

The creep tests on both alloys were analyzed to determine the stress and temperature dependence of creep deformation in the temperature range 650 to $870^{\circ} \mathrm{C}$. Measurements of apparent stress exponent $n$ were made by decreasing the load during testing in order to provide a step change in stress and thus strain rate. ${ }^{24)}$ At each new stress level, the test continued until a new steadystate creep rate could be determined, thus minimizing structural changes for each successive decrease in load. Most tests were terminated during steady-state creep. For materials which undergo power-law creep, according to the usual equation,

$$
\dot{\varepsilon}_{s}=A \sigma^{n} e^{-Q_{c / R T}},
$$

where $\dot{\varepsilon}_{s}$ is the steady-state creep rate at a tensile stress $\sigma, n$ and $A$ are constants, $Q_{c}$ is the apparent activation energy, $R$ the gas constant, and $T$ the absolute temperature. Therefore, plotting log of steady-state creep rate $v s . \log \sigma$ will result in a straight line with a slope equal to $n$, the power-law exponent. ${ }^{25-27)}$

The results for the role of microstructure for both Ti-24-11 and Ti-25-10-3-1 can be illustrated with the two examples in Fig. 3. In each case, a single test temperature is used to compare various starting microstructures, with specimen codes identified in the figure caption. Similarly, the effects of temperature on any one microstructure can be compared as in the examples 
(a)

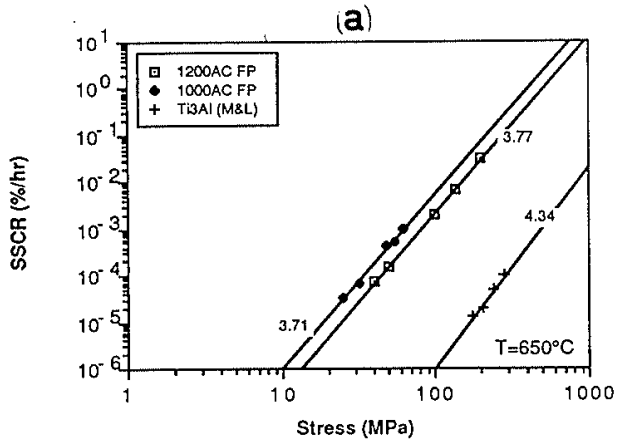

(b)

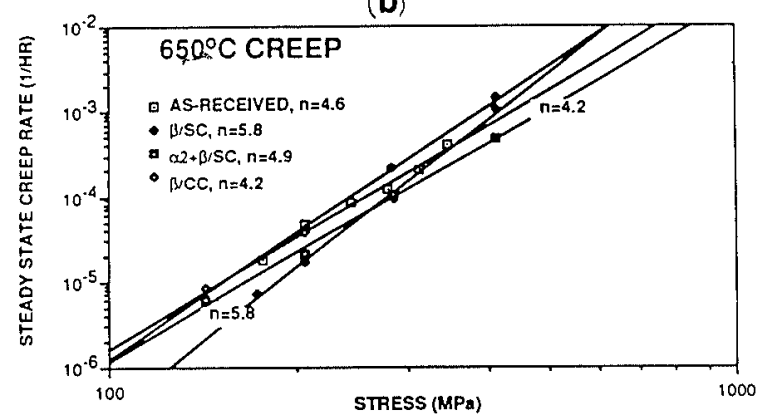

Fig. 3. Stress dependence of creep in two aluminide alloys. (a) Creep rate $v s$. stress for Ti-24-11 at $650^{\circ} \mathrm{C}$; " 1200 $\mathrm{AC}$ " refers to $\beta / \mathrm{AC}$ treatment, " $1000 \mathrm{AC}$ " to $\alpha_{2}+\beta /$ AC. Also shown is result for stoichiometric $\mathrm{Ti}_{3} \mathrm{Al}$ from Ref. 10). Data from Ref. 17). (b) Creep rate vs. stress in Ti-25-10-3-1 for several microstructures (individual stress exponents, $n$, shown). From Ref. 16).

of Fig. 4. It is evident in Figs. 3 and 4 that two patterns of stress dependence were observed, either a constant value of $n$ or a varying $n$ value. In the latter cases, the data appeared to be adequately described by a two-part linear fit, i.e. two $n$ values.

Increasing creep test temperature generally led to slightly decreased values of $n$. At lower temperatures and lower stresses, the abrupt change in stress exponent in some cases may be an indication of a transition in rate-controlling mechanism. Higher values of $n$, in the range of 4 to 5 for single-phase materials and up to as much as 11 in two-phase or multi-phase materials, are usually accepted as indicating diffusion-controlled dislocation creep processes. ${ }^{28-30}$. On the other hand, a value of $n$ near or equal to unity indicates diffusional creep by a stress-directed flow of atoms with grain boundaries acting as sources and sinks, with this process occurring at low to intermediate stresses, $\sigma=\left(10^{-5}\right.$ to $\left.10^{-4}\right) E$, where $E$ is the Young's modulus. ${ }^{30,31)}$ The low stress slopes of the present aluminide materials, Figs. 3 and 4, approximate the slope of the curves at high temperatures, where diffusion processes are dominant. Elevation of the low-stress creep rates (relative to an extrapolation of behavior at high stress) may occur due to some contribution of grain (or phase) boundary sliding or diffusional creep to the overall creep rate. ${ }^{31-34)} \mathrm{A}$ value of $n=2$ has been taken to indicate a contribution to the creep rate from grain (or phase) boundary sliding mechanisms. ${ }^{32)}$

The gradual reduction in stress exponent with (a)

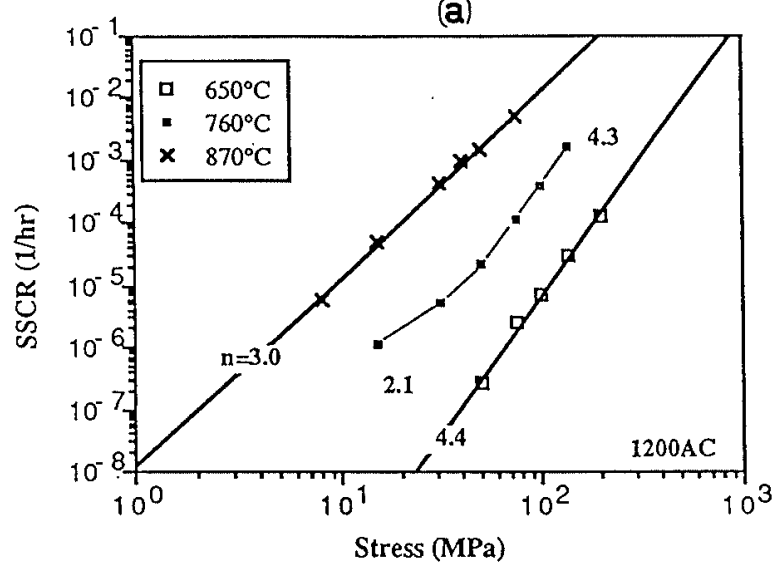

(b)

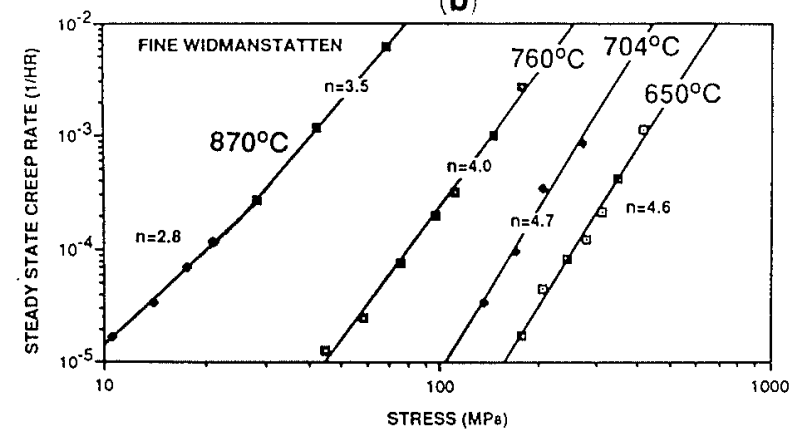

Fig. 4. Temperature effect on stress dependence of creep in the same alloys as Fig. 3, shown in form of creep rate vs. stress curves. In each case, note change of slope in some tests. (a) Example for $\mathrm{Ti}-24-11$, the $\beta / \mathrm{AC}$ microstructure, from Ref. 17). (b) Example for Ti-25-10-3-1, for fine Widmanstätten structure, Ref. 16).

increasing temperature, Fig. 4, may also have occurred if boundary sliding were to emerge as an important process and thus the exponent, $n$, would decrease, since grain boundary sliding tends to decrease $n$, relative to a material without grain boundary sliding. ${ }^{32)}$ Because boundary sliding is not an independent mechanism producing a steady-state creep strain and must be integrally connected with intra-crystalline creep deformation, ${ }^{25,30,33)}$ it is possible that two mechanisms are operative at the highest test temperature used, $870^{\circ} \mathrm{C}$.

\subsection{Temperature Dependence}

In addition to the stress exponent $n$, the apparent activation energy $Q_{c}$ is considered helpful ${ }^{29,35)}$ in establishing the controlling mechanism of creep deformation. In Fig. 5, plots of steady-state creep rate vs. temperature are shown. Again, assuming power-law creep, Eq. (1), when the log of creep rate is plotted against $1 / T$, a straight line results, with a slope equal to $Q_{c}$. There have been several determinations of $Q_{c}$ for Ti-24-11. The activation energy in the low stress regime for Ti-24-11 with a $100 \%$ transformed $\beta$ microstructure was found to be $120 \mathrm{~kJ}^{36)}$ under conditions of $n=1$, while an $\alpha_{2}+\beta$ microstructure exhibited a value of $259 \mathrm{~kJ} / \mathrm{mol},{ }^{12)}$ in the stress range of 103 to $138 \mathrm{MPa}$. In the work described here, ${ }^{17)} Q_{c}$ values ranged from $110 \mathrm{~kJ} / \mathrm{mol}$ for as-received material, to the $142 \mathrm{~kJ} / \mathrm{mol}$ for the $\alpha_{2}+\beta$ microstructure, 

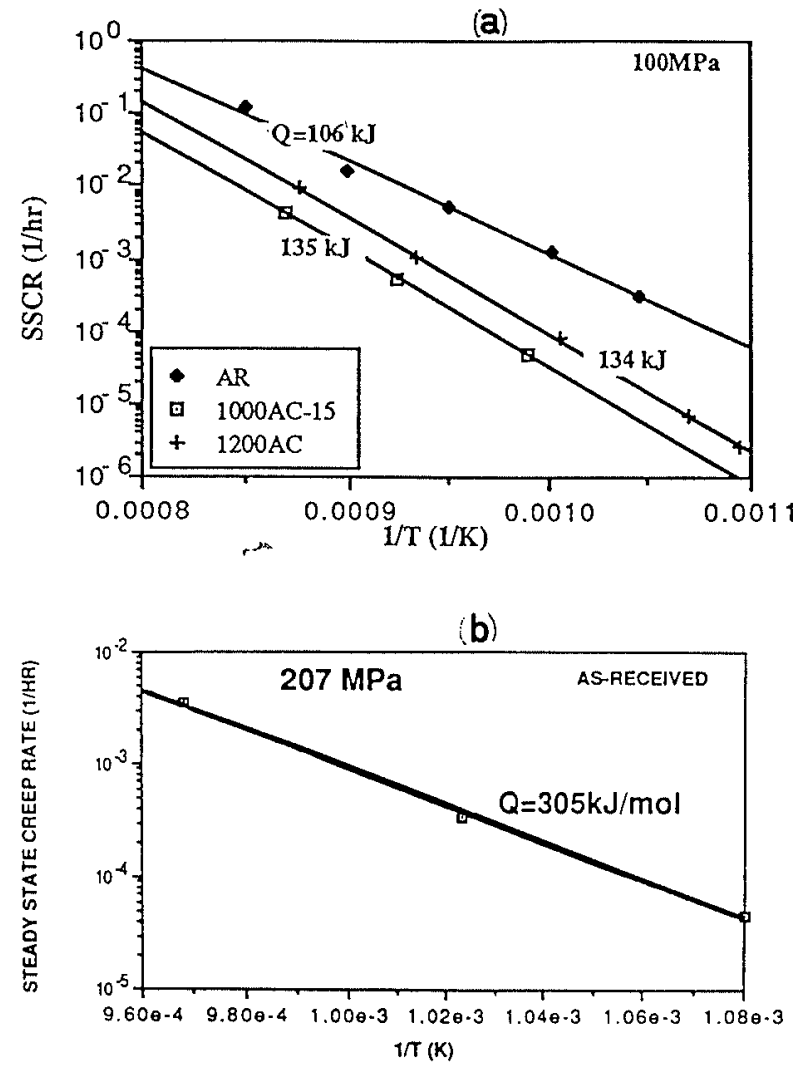

Fig. 5. Creep activation energy determinations, from creep rate $v s .1 / T$ plots. (a) Data for Ti-24-1I at stress of $100 \mathrm{MPa}$ (average slope values in text are averages of determinations at several stresses), from Ref. 17). (b) Data for fine Widmanstätten microstructure of Ti-25-10-3-1, at $207 \mathrm{MPa}$, from Ref. 16).

and $134 \mathrm{~kJ} / \mathrm{mol}$ for the $\beta$ solution treated structure. All values were measured in the low stress regime (below $100 \mathrm{MPa}$ ), and are in fairly good agreement with the activation energy for diffusional creep $(n=1)$ of $121 \mathrm{~kJ} / \mathrm{mol}$ in fine-grained $\alpha$ titanium at stresses below $2 \mathrm{MPa} .{ }^{37)}$ This latter value was attributed to grain boundary diffusion. Values for self-diffusion, pipe diffusion, or grain boundary diffusion in $\alpha_{2}$ alloys are not available, either for the $\alpha_{2}$ phase or for the $\beta$ phase. The $\beta$ phase data may be of particular interest, since, as discussed below, the plasticity of the $\beta$ phase plays an important role in deformation of $\alpha_{2}$ aluminide alloys at both low and high temperatures.

A creep activation energy of $206 \mathrm{~kJ} / \mathrm{mol}$ for stoichiometric $\mathrm{Ti}_{3} \mathrm{Al}$ at all stresses and temperatures has been measured, ${ }^{10)}$ while addition of $10 \mathrm{w} / \mathrm{o} \mathrm{Nb}$ to the stoichiometric $\alpha_{2}$ increased $Q_{\mathrm{c}}$ to $285 \mathrm{~kJ} / \mathrm{mol} .{ }^{10)}$ The Ti-25-10-3-1 alloy, with considerably more $\beta$ stabilizer content, was found to have a $Q_{c}$ of $305 \mathrm{~kJ} / \mathrm{mol}^{16)}$ in the climb-controlled creep regime. This value of $Q_{c}$, although large compared to the roughly $125 \mathrm{~kJ} / \mathrm{mol}$ values for Ti-24-11, may reflect a different activation energy for diffusion, or a changing rate-controlling diffusion path or process. It has been concluded that the apparent activation energies for high temperature creep in metals should be independent of creep stress and strain, ${ }^{38)}$ but different mechanisms seem to be dominant in different stress regimes. It has been suggested that the activation energy for both crystallographic slip and boundary sliding are the same and that slip may control sliding, ${ }^{39}$ ) since, as mentioned, sliding is not an independent process in creep. ${ }^{25,30,33)}$ More work appears to be needed to clarify the source of high $Q_{\mathrm{c}}$ values in $\alpha_{2}$ alloys, including the role of $\beta$ stabilizing elements in both diffusivity values and in ordering of the $\beta$ phase, microstructure, and diffusion paths. ${ }^{10,16,17)}$ Ordered or disordered $\beta$ phase, varying interphase boundary composition, and relative plasticity of the $\alpha_{2}$ and $\beta$ phases, could all be relevant to establishing the creep mechanism(s) in these alloys.

\subsection{Microstructural Effects}

The role of cooling rate in Fig. 2 can apparently be interpreted in the following way. A phenomenological model ${ }^{6,40\}}$ was recently proposed to interpret creep behavior of near- $\alpha$ titanium alloys in terms of microstructural factors. Observation of an optimum cooling rate for maximum creep resistance was explained in this model in terms of the trade-off between two factors: an increasing amount of retained $\beta$ phase (detrimental in creep resistance) and decreasing $\alpha$ plate size (beneficial in creep resistance). The present observations for Ti25-10-3-1 on the interaction between microstructure and creep deformation can be rationalized using the same two factors for near- $\alpha$ titanium alloys.

One important factor is that the effective slip length in elevated temperature creep deformation is evidently controlled by primary $\alpha_{2}$ size in $\alpha_{2}+\beta$ processed microstructures and by Widmanstätten $\alpha_{2}$ in $\beta$ processed microstructures. Even though the Burgers relationship is expected to exist between $\alpha_{2}$ and ordered $\beta$ phase, as it does between $\alpha$ and $\beta$ phase, ${ }^{41,42)}$ it is not surprising that $\alpha_{2} / \mathrm{B}_{2}$ boundaries are effective barriers to slip and act to confine active dislocations to individual $\alpha_{2}$ platelets, because of the relatively low applied stresses necessitated by the high creep temperatures. Therefore, inferior creep resistance of the $\alpha_{2}+\beta / \mathrm{SC}$ microstructure is attributed to a larger slip length than that of the $\beta / \mathrm{SC}$ microstructure.

However, $\alpha_{2}$ plate size alone is not the sole controlling factor in creep deformation. If it were, it would be expected that the microstructure with fine Widmanstätten $\alpha_{2}$ platelets would exhibit superior creep resistance. The maximum in creep resistances that occurs ${ }^{16)}$ in the slow cooled microstructure $(\beta / \mathrm{SC})$ at 760 and $650^{\circ} \mathrm{C}$ and low stresses suggests that another microstructural factor, competing with $\alpha_{2}$ plate dimension, is present. That factor is the amount of retained ordered $\beta$ phase $\left(B_{2}\right)$. Fast cooling increases the amount of $\mathrm{B}_{2}$ phase, ${ }^{22,23)}$ believed to be present in Ti-25-10-3-1, thus resulting in poor creep resistance, because of its ductility and intrinsic high diffusion coefficient. It is, therefore, required to have optimum $\alpha_{2}$ plate size and optimum amount of retained $\mathrm{B}_{2}$ phase for superior creep resistance at elevated temperatures. If the $\beta$ phase is disordered, these factors may be different. At $650^{\circ} \mathrm{C}$ and high stresses, however, a somewhat complicated role of microstructure was observed. ${ }^{16)}$ The low creep resistance in $\beta / \mathrm{SC}$ microstructure in this regime suggests that a different structural unit beyond $\alpha_{2}$ plate size was effective, similar to that of 
room temperature tensile behavior, ${ }^{5,13}$ ) or that the thermally activated deformation process in retained $B_{2}$ phase was not significant in controlling creep deformation at this temperature. Thus creep at $650^{\circ} \mathrm{C}$, Fig. 2(a), can be regarded as a transition between patterns of lower temperature deformation and those of high temperature creep deformation.

These interpretations are supported by dislocation structure and fractographic results. ${ }^{16)}$ The predominant dislocation type had a Burgers vectors, i.e. $\langle 11 \overline{2} 0\rangle$, predominantly on prism planes, at both room and elevated temperatures, as has also been shown by several other investigators. ${ }^{5,13,43,44)}$ Extensive cross-slip of these dislocations torbasal and pyramidal planes at the higher temperatures was observed, ${ }^{16)}$ again in agreement with prior work. Other dislocations, evidently $\mathbf{c}+\mathbf{a}$ type, were also observed. ${ }^{13,16,44)}$ Fractographic examination showed clearly that the retained $\beta$ or transformed $\beta$ constituent acted in a relatively ductile manner, compared to the cleavage-like fracture of the $\alpha_{2}$ phase, both at room and elevated temperature. ${ }^{16,18,45)}$ This result is also in accord with deformation studies. ${ }^{44)} \mathrm{At}$ $750^{\circ} \mathrm{C}$ and above, some intergranular fracture was also noted, in accord with prior work. ${ }^{43}$

Turning from the $\mathrm{Ti}-25-10-3-1$ results of Fig. 2 to the pattern of results for $\mathrm{Ti}-24-11$, similar concepts should be applicable. Recrystallization and grain growth during creep, $\alpha$ plate width, $\beta$ volume fraction, and $\alpha / \alpha$ vs. $\beta / \beta$ boundaries are all factors that are thought to influence steady-state creep rate in conventional titanium alloys. ${ }^{6)}$ If only $\alpha_{2}$ plate size were considered to control steady-state creep rate in titanium aluminides, a concept that was shown above to be inadequate to describe creep in $\mathrm{Ti}-25-10-3-1$, then we would expect the microstructure with the smallest plates, that is, the $\beta / \mathrm{AC}$ and $\alpha_{2}+\beta / \mathrm{AC}-15$ structures (" 15 " designates the solution treatment time in minutes), to have the best creep resistance, due to their short slip length. It is seen, however, that $\alpha_{2}+\beta / \mathrm{AC}-30$ (30 min solution treatment), with coarser $\alpha_{2}$ plates, has superior creep resistance up to $870^{\circ} \mathrm{C}$. Therefore, slip distance and corresponding dislocation motion within plates is not the sole controlling factor in creep of $\mathrm{Ti}-24-11$ in the temperature and stress range studied. Rather, since the $\alpha_{2}+\beta / \mathrm{AC}-30$ plates are coarser than the plates present in the other microstructures, then it is true that there is less interphase boundary per unit area in this stucture. The ratio $\varepsilon_{g b} / \varepsilon_{t}$, the strain due to grain boundary sliding to the total creep strain, was found to increase with increasing temperatures $^{39)}$ or decreasing stresses. ${ }^{46)}$ Also, the $\alpha_{2}+\beta / \mathrm{AC}$ structures should contain smaller amounts of $\beta$ phase, a factor which is comparable to that invoked in discussing Ti-25-10-3-1 above. This phase has a higher diffusion rate and thus, inferior creep resistance. This would explain the fact that $\alpha_{2}+\beta / \mathrm{AC}$ structures creep more slowly than the $\beta / \mathrm{AC}$ structure. Examination of microstructures in crept specimens ${ }^{17)}$ demonstrated that recrystallization and grain growth did not occur appreciably during creep. The presence of crystallographic texture, e.g. an alignment in basal planes in processing, could help explain the high steady-state creep rate of as- received material.

\subsection{Comparison to Other Alloys}

The creep behavior of several $\alpha_{2}$-based alloys is compared at $650^{\circ} \mathrm{C}$ in Fig. 6. Three results for Ti-24-11 are included, ${ }^{12,17,36)}$ as well as a stoichiometric $\mathrm{Ti}_{3} \mathrm{Al}$ result ${ }^{10)}$ and one set of data for Ti-25-10-3-1. ${ }^{16)}$ A line for the $\beta / \mathrm{AC}$ microstructure in Ti-24-11 is included, as a fairly typical result among the data shown. It is evident that the $\mathrm{Ti}_{3} \mathrm{Al}$ and $\mathrm{Ti}-25-10-3-1$ have somewhat better creep resistance (about one order of magnitude lower creep rate) than the Ti-24-11 data shown.

In Fig. 7, creep behavior of Ti-25-10-3-1 is compared at 650 and $760^{\circ} \mathrm{C}$ with those of two near- $\alpha$ titanium alloys, Ti-6242S ${ }^{6)}$ and Ti-1100, ${ }^{16)}$ the latter of which is

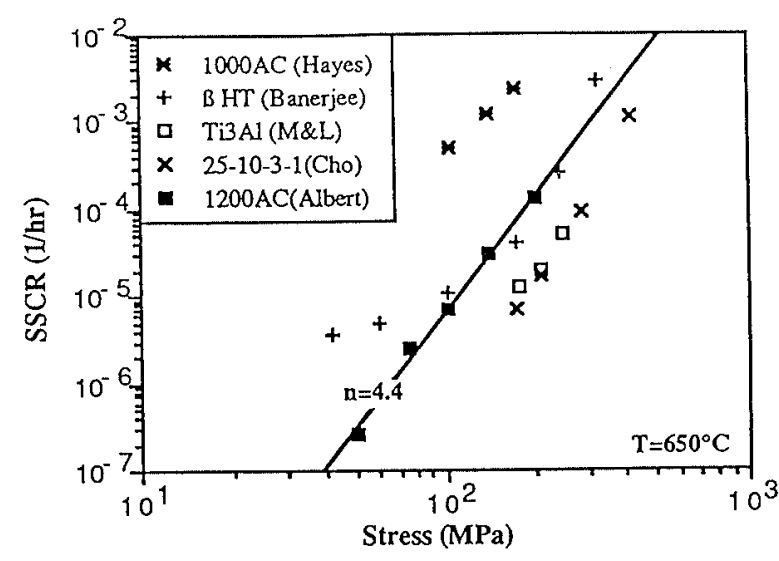

Fig. 6. Comparison of creep in several titanium aluminide alloys. Data for Ti-24-11 of Hayes, ${ }^{12)}$ Albert ${ }^{17)}$ and Banerjee ${ }^{35)}$; Ti-25-10-3-1 from Ref. 16); and $\mathrm{Ti}_{3} \mathrm{Al}$ from Ref. 10).

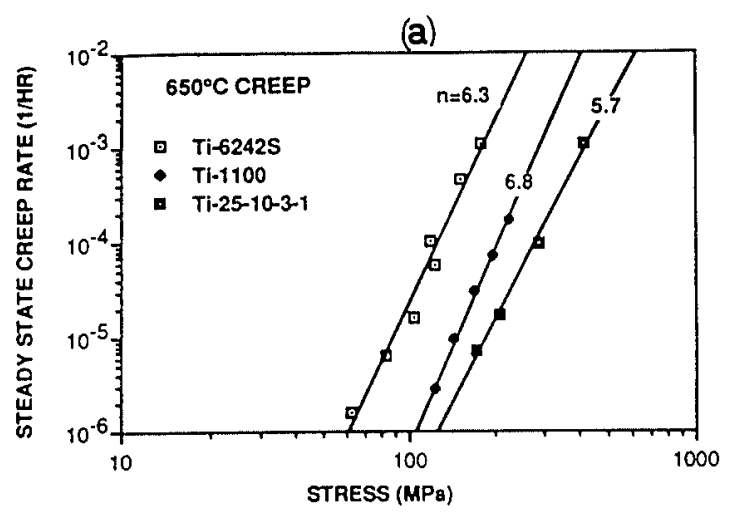

(b)

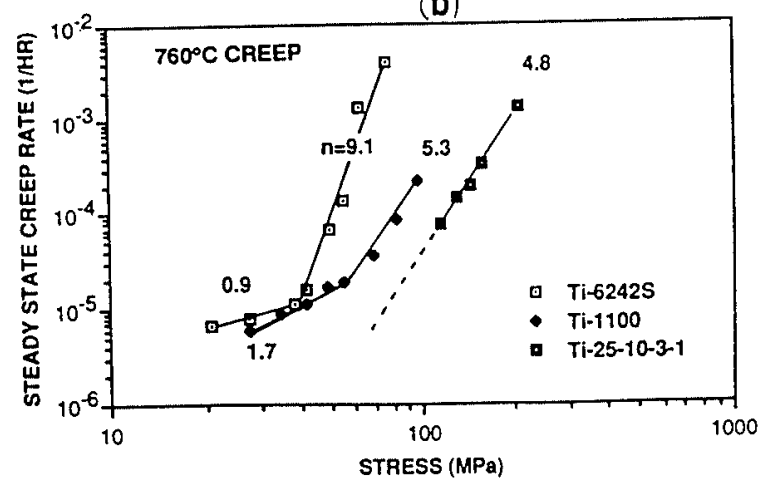

Fig. 7. Comparison of creep in several titanium and aluminide alloys. Data for Ti-6242S $\mathrm{S}^{6)}$ and Ti-1100 ${ }^{16)}$ compared to $\mathrm{Ti}-25-10-3-1^{16)}$ at two temperatures. 
a newly-developed alloy which achieves improved creep resistance with $0.45 \% \mathrm{Si}, \mathrm{known}^{24)}$ to provide creep resistance, and smaller amounts of $\beta$ phase stabilizers. For this comparison, the optimum microstructure (colony) was used for all alloys. Generally, creep resistance of Ti-25-10-3-1 is improved by one order of magnitude over Ti-1 100 and by two orders of magnitude over Ti-6242S. Unlike near- $\alpha$ alloys, a transition in mechanism in $\mathrm{Ti}-25-10-3-1$ was not found at $760^{\circ} \mathrm{C}$ in the similar stress range studied. At the lower temperature, $650^{\circ} \mathrm{C}$, deformation mechanisms appear to be similar to those observed at lower temperature, ${ }^{5,13,44,47)}$ as noted above. As mentioned above, the possibly varying roles of $\beta$ phase in the aluminide alloys would make it most valuable to test alloys of varying $\beta$ stabilizer content, particularly if the degree of order of the $\beta$ varies.

\section{Conclusions}

(1) Microstructural effects on creep behavior of two titanium aluminide alloys based on $\mathrm{Ti}_{3} \mathrm{Al}, \mathrm{Ti}-24-11$ and $\mathrm{Ti}-25-10-3-1$, has been examined in some detail as a function of stress and temperature $\left(650-870^{\circ} \mathrm{C}\right)$.

(2) It is believed that $650^{\circ} \mathrm{C}$ creep shows a transition deformation behavior between room temperature and elevated temperature behavior. At temperatures above $650^{\circ} \mathrm{C}, \beta$ solution treated microstructures exhibited superior creep resistance compared to $\alpha_{2}+\beta$ processed microstructure $\left(\alpha_{2}+\beta / \mathrm{SC}\right.$ vs. $\left.\beta / \mathrm{SC}\right)$ unless $\alpha_{2}$ plates were coarsened by extending solution treatment in the $\alpha_{2}+\beta$ field.

(3) A pronounced influence of cooling rate from the $\beta$ solution treatment temperature of creep was observed in $\mathrm{Ti}-25-10-3-1$. At $760^{\circ} \mathrm{C}, \beta / \mathrm{SC}$ (colony) was proven to be an optimum microstructure for creep resistance at all stresses studied. However, at $650^{\circ} \mathrm{C}$, possibly representing transition deformation behavior, a somewhat complicated effect that depends on stress level was found. At this temperature, $\beta / \mathrm{SC}$ shows superior creep performance only at relatively low stresses. The degree of order, and the relative plasticity, of the $\beta$ phase may be important in these effects, and deserves further study.

(4) The stress exponent $n$ tended to decrease with increasing temperature. At higher temperatures, some microstructures also exhibited an apparent transition in creep mechanism, depending on stress level. The obtained $n$ values are generally within the range of values predicted by theoretical models of dislocationcontrolled creep. A creep activation energy of $305 \mathrm{~kJ} / \mathrm{mol}$ was measured for Ti-25-10-3-1, and values of about $125 \mathrm{~kJ} / \mathrm{mol}$ were obtained for $\mathrm{Ti}-24-11$. Reasons for the large difference in values are not known, and may reflect major differences in behavior of $\beta$ phase or of interphase boundaries, or possibly a major of role of stress level.

(5) Creep resistance of Ti-25-10-3-1 was compared to $\mathrm{Ti}-24-11$ and to two creep-resistant near- $\alpha$ titanium alloys, and was found to be improved by one or two orders of magnitude over each, in the test regimes studied, when the optimum microstructure (colony) is used for all alloys. The Ti-25-10-3-1 alloy is also similar to or superior to stoichiometric $\mathrm{Ti}_{3} \mathrm{Al}$ in the creep tests discussed here.

\section{Acknowledgments}

We appreciate helpful discussions with J. C. Williams and W. Cho, and provision of unpublished results by D. E. Albert. Support of the experimental work described here was provided by the U.S. Air Force Office of Scientific Research, both under contract F49620-87-C0017 , as part of the University Research Initiative program on High Temperature Metal Matrix Composites at Carnegie Mellon University, and under grant AFOSR 90-0033.

\section{REFERENCES}

1) H. A. Lipsitt: High-Temperature Ordered Intermetallic Alloys, MRS Symp., Vol. 39, ed. by C. C. Koch, C. T. Liu and N. S. Stoloff, MRS, Pittsburgh, (1985), 351.

2) R. L. Fleischer, D. M. Dimiduk and H. A. Lipsitt: Ann. Rev. Mater. Sci., 19 (1989), 231.

3) M. J. Blackburn, D. L. Ruckle and C. E. Bevan: Research to Conduct an Analytical Investigation of Alloys, Technical Report AFML-TR-78-18, Air Force Mater. Lab., Wright-Patterson AFB, Ohio, (1978).

4) M. J. Blackburn and M. P. Smith: R \& D on Composition and Processing of Titanium Aluminide Alloys for Turbine Engines, Technical Report, AFWAL-TR-82-4086, Air Force Wright Aeronautical Lab., Wright-Patterson AFB, Ohio, (1982).

5) Y.-W. Kim and F. H. Froes: High Temperature Aluminides and Intermetallics, ed. by S. H. Whang, C. T. Liu, D. P. Pope and J. O. Stiegler, TMS-AIME, Warrendale, (1990), 465.

6) W. Cho, J. W. Jones, J. E. Allison and W. T. Donlon: Proc. Sixth Int. Conf. on Titanium, Vol. 1, ed. by P. Lacombe, R. Tricot and G. Beranger, Les Editions de Physique, Paris, (1989), 187

7) P. A. Blenkinsop, D. F. Neal and R. E. Goosey: Titanium and Titanium Alloys, Proc. Third Int. Conf. on Titanium, Vol. 3, ed. by J. C. Williams and A. F. Belov, Plenum, New York, (1982), 2003.

8) C. C. Chen and J. E. Coyne: Titanium ' 80 Science and Technology, Proc. Fourth Int. Conf. on Titanium, Vol. 2, ed by H. Kimura and O. Izumi, TMS-AIME, Warrendale, (1980), 1197.

9) P. A. Blenkinsop: Titanium, Science and Technology, Proc. Fifth Int. Conf. on Titanium, ed. by G. Lütjering, U. Zwicker and W. Bunk. DGM, Oberursel, (1985) 2323.

10) M. G. Mendiratta and H. A. Lipsitt; J. Mater. Sci., 15 (1980), 2985

11) C. G. Rhodes: Proc. Sixth Int. Conf. on Titanium, Vol. I, ed. by P. Lacombe, R. Tricot and G. Beranger, Les Editions de Physique, Paris, (1989), 199.

12) R. W. Hayes: Scr. Metall., 23 (1989), 1931.

13) D. A. Koss, D. Banerjee, D. A. Lukasak and A. K. Gogia: High Temperature Aluminides and Intermetallics, ed. by S. H. Whang, C. T. Liu, D. P. Pope and J. O. Stiegler, TMS-AIME, Warrendale, (1990), 175.

14) R. G. Rowe: High temperature Aluminides and Intermetallics, ed. by S. H. Whang, C. T. Liu, D. P. Pope and J. O. Stiegler, TMS-AIME, Warrendale, (1990), 375.

15) J. M. Larsen, K. A. Williams, S. J. Balsone and M. A. Stucke: High Temperature Aluminides and Intermetallics, ed. by S. H. Whang, C. T. Liu, D. P. Pope and J. O. Stiegler, TMS-AIME, Warrendale, (1990), 521.

16) W. Cho, A. W. Thompson and J. C. Williams: Metall. Trans. A, 21A (1990), 641

17) D. E. Albert and A. W. Thompson: Creep Behavior of Ti-24Al$\mathrm{IlNb}$, Microstructure/Property Relationships in Titanium Alloys and Titanium Aluminides, ed. by Y.-W. Kim, R. R. Boyer and $\mathbf{J}$. A. Hall, TMS-AIME, Warrendale, in press.

18) C. H. Ward, J. C. Williams, A. W. Thompson, D. G. Rosenthal and F. H. Froes: Proc. Sixth Int. Conf. on Titanium, Vol. 2, ed. by $\mathrm{P}$. Lacombe, R. Tricot and G. Beranger, Les Editions de 
Physique, Paris, (1989), 1103.

19) T. Hamajima, G. Lütjering and S. Weissmann: Metall. Trans, 4 (1973), 847

20) D. Banerjee, T. K. Nandi and A. K. Gogia: Scr. Metall., 21 (1987), 597.

21) D. Banerjee, A. K. Gogia, T. K. Nandi and V. A. Joshi: Acta Metall., 36 (1988), 871.

22) R. Strychor, J. C. Williams and W. A. Soffa: Metall. Trans. A, 19A (1988), 225.

23) R. Strychor: $\beta$ Phase Decomposition in Ti-Al-Nb Alloys, Ph. D. Thesis, Carnegie Mellon University, Pittsburgh, (1990).

24) N. E. Paton and M. W. Mahoney: Metall. Trans. A, 7A (1976), 1685.

25) S. Takeuchi and A. S. Argon: J. Mater. Sci., 11 (1976), 1542.

26) A. M. Brown and M. F. Ashby: Scr. Metall., 14 (1980), 1297.

27) B. Walser and $Q$. D. Sherby: Scr. Metall., 16 (1982), 213.

28) J. Weertman: Trans. Am. Soc. Met., 61 (1968), 681.

29) W. D. Nix and B. Ilschner: Strength of Metals and Alloys, Proc. ICSMA 5, ed. by P. Haasen, V. Gerold and G. Kostorz, Pergamon, New York, (1980), 1507.

30) H. J. Frost and M. F. Ashby: Deformation Mechanism Maps: The Plasticity and Creep of Metals and Ceramics, Pergamon Press, Oxford, (1982), 11.

31) R. Raj and M. F. Ashby: Metall. Trans., 2 (1972), 1113.

32) H. Lüthy, R. A. White and O. D. Sherby: Mater. Sci. Eng., 39 (1979), 211.

33) F. W. Crossman and M. F. Ashby: Acta Metall., 23 (1975), 425.

34) H. Riedel: Fracture at High Temperature, Springer-Verlag, New
York, (1987)

35) R. Lagneborg: Int. Metall. Rev., 17 (1972), 130.

36) R. S. Mishra and D. Banerjee: Mater. Sci. Eng., A130 (1990), 151.

37) G. Malakondaiah and R. Rama Rao: Acta Metall., 29 (1981), 1263.

38) A. K. Mukherjee, J. E. Bird and J. E. Dorn: Trans. Am. Soc. Met., 62 (1969), 155.

39) D. McLean and M. H. Farmer: J. Inst. Met., 85 (1957), 41.

40) W. Cho: Creep Behavior of Near- $\alpha$ Titanium Alloys, Ph. D. Thesis, The University of Michigan, Ann Arbor, MI, (1987).

41) J. C. Williams: Titanium Science and Technology, Proc. Second Int. Conf. on Ti, Vol. 3, ed. by R. I. Jaffe and H. M. Burte, eds., Plenum Press, New York, (1973), 1433.

42) J. C. Williams and G. Lütjering: Titanium ' 80 , Science and Technology, Proc. Fourth Int. Conf. on Titanium, Vol. 1, ed. by H. Kimura and O. Izumi, TMS-AIME, Warrendale, (1980), 671.

43) H. A. Lipsitt, D. Shechtman and R. E. Schafrik: Metall. Trans. $A, 11$ A (1980), 1369

44) B. J. Marquardt, G. K. Scarr, J. C. Chesnutt, C. G. Rhodes and H. L. Fraser: Proc. Sixth Int. Conf, on Titanium, Vol. 2, ed. by P. Lacombe, R. Tricot and G. Beranger, Les Editions de Physique, Paris, (1989), 955.

45) K. S. Chan: Metall. Trans. A, 21A (1990), 2687.

46) D. McLean: J. Inst. Met., 81 (1952-53), 293.

47) S. J. Gittis and D. A. Koss: High-Temperature Ordered Intermetallic Alloys III, MRS Symp. 133, ed. by C. T. Liu, A. I. Taub, N. S. Stoloff and C. C. Koch, MRS, Pittsburgh, (1989), 323. 